\title{
Outcomes of community-based suicide prevention program in primary health care of Iran
}

Hosein Azizi 1,2,3* ${ }^{*}$, Ali Fakhari ${ }^{2,4}$, Mostafa Farahbakhsh², Elham Davtalab Esmaeili5 and Mohammad Mirzapour ${ }^{6}$

\begin{abstract}
Background: Suicidal management and prevention in communities, especially in its first stages, is an effective intervention for the health systems. However, in numerous societies most cases go undetected. Primary Health Care (PHC) is an effective place for the management of Suicide Prevention Programs (SPP). In Malekan County, a health community assessment found suicide as the most important health problem. A regional SPP was performed for suicide prevention during 2014-2017.
\end{abstract}

Methods: This study was carried out in six steps: (1) Establishing a research team, (2) Improving a registry for suicidal behaviors (SBs), (3) Identifying local determinants of SBs, (4) Training healthcare providers, (5) Follow-up and monitoring of SBs, and (6) Public awareness campaigns. Our ultimate goal was to lower the rates of suicide, and suicide attempt (SA) by 15 and $20 \%$, respectively. Multiple logistic regression was used to estimate the adjusted odds ratios and the $95 \%$ confidence intervals.

Results: A total of 821 SAs and 32 suicides were identified. The gender distribution for suicides was $70 \%$ males whereas SAs were 64\% among females. The majority of suicides occurred in spring 18 (56.25\%) while summer was the most common season among SAs 288 (35.8\%). Almost 62 and 75\% of suicides and SAs have used hanging and poisoning methods, respectively. Hanging increased suicide risk significantly (OR: 8.5, 95\% Cl 2.9-76.99). During the study, 93 life-skill and parenting education sessions were held. The incidence rates of suicide and SA decreased from 11.22, and 203 per 100,000 in 2013 to 2.63, and 157 in 2017, respectively. Similarly, the re-attempt to SAs ratio decreased from 12\% to 2013 to $6.7 \%$ in 2017. Moreover, more than 8\% of SBs were collected from adjacent Counties.

Conclusions: At the study end, suicide, SA, and re-attempt were lowered by $75 \%, 22 \%$, and $42 \%$, respectively. The practical framework that achieved in this study could be used as a basis for developing future SPPs and suicide researches in the Iranian context. Furthermore, the various socio-economic and socio-cultural challenges highlight the need to consider a wide range of contextual factors when developing an SPP.

Keywords: Suicide prevention program, Primary health care, Re-attempt, Iran, Suicide, Self-injurious behavior

\footnotetext{
*Correspondence: epid_azizi@yahoo.com; azizih@razi.tums.ac.ir ${ }^{1}$ Social Determinants of Health Research Center, Health Management and Safety Promotion Research Institute, Tabriz University of Medical Sciences, Tabriz, Iran

Full list of author information is available at the end of the article
}

\begin{abstract}
Background
Suicidal management and prevention in communities, especially in its first stages, is an important intervention for health care system. Yet, in many societies most cases go undetected [1]. The degree of underreporting varied (overall: $10-30 \%$ ) across countries [2]. In Norway and Finland, almost $10 \%$ of suicide cases could have been misclassified. However, in Malaysia
\end{abstract} original author(s) and the source, provide a link to the Creative Commons licence, and indicate if changes were made. The images or other third party material in this article are included in the article's Creative Commons licence, unless indicated otherwise in a credit line to the material. If material is not included in the article's Creative Commons licence and your intended use is not permitted by statutory regulation or exceeds the permitted use, you will need to obtain permission directly from the copyright holder. To view a copy of this licence, visit http://creativecommons.org/licenses/by/4.0/. The Creative Commons Public Domain Dedication waiver (http://creativeco mmons.org/publicdomain/zero/1.0/) applies to the data made available in this article, unless otherwise stated in a credit line to the data. 
and Egypt, the actual suicide cases could be more than $100 \%$ higher than the official suicide statistics [2, 3]. It is estimated that every year more than 1 million people die by suicide in the world, but these numbers are the tip of the iceberg and it is under-reported due to the lack of an effective Suicide Prevention Program (SPP), cultural stigma and the absence of registry for suicide $[4,5]$. Despite these limitations, suicide is the second leading cause of mortality among people aged 15-29 years [6]. Suicide is the tenth cause of death in the United States where annually more than 35,000 deaths are attributed to suicide [7].

However, suicide and suicidal behaviors (SBs), are markedly challenging to be reliably tracked in health care and surveillance systems. The difficulty in documenting suicide has contributed to the lack of initiation and sustainment of SPP globally [5, 8]. Global suicide death reporting systems require significant improvement to provide valid and reliable data to design and implement programs $[9,10]$. Since 2013, the World Health Organization (WHO) has had a global mental health action plan for reducing the rate of suicide by $10 \%$ in the world by 2020 , but merely $18 \%$ of countries have a registry for suicide.

Primary Health Care (PHC) system is an effective and appropriate place for developing and management of SPPs. PHC services are the most readily available means of health care which are accessible and with high rates of regular contact so that many health service providers in primary care can play a noticeable role in suicide prevention [11].

In Iran, suicide is considered the fifth cause of death [12]. The incidence rate of suicide has increased over the past decades, especially in East Azarbaijan Province where there are limited studies on the subject [13]. Iran has a suicide rate between 1.4 and 29.6 per 100,000 population [14].
According to the report of the WHO, SPP is not only critical for persons and families but moreover it hugely profits the health care system and welfare of communities and society [15]. A community health assessment indicated that $\mathrm{SB}$ is the most important health problem in Malekan County, East Azarbaijan. A regional SPP was developed and implemented for suicide and SB prevention in the PHC setting during the period 2014-2017 years $[13,16]$. The findings and implications of this interventional study can be useful for health care systems. Therefore, the main objective of this paper is to outline the findings and outcomes of this interventional program in the reduction of suicide and SB.

\section{Methods}

\section{Study design and setting}

A regional community-based SPP was performed for suicide and SB prevention in PHC system of Malekan County, East Azarbaijan Province, Iran during 20142017. Malekan County is located in the northwest of Iran with 117,000 population in 2018 (Fig. 1). Native language of all its population is Azeri and all of them are Muslims. Almost, $70 \%$ of the County population live in rural areas. Their main occupations are farming or farming-related.

Community health needs assessment by the health network of Malekan County revealed that suicide and SBs are among the most important public health concerns. This community health assessment was performed in 8 steps based on North Carolina community assessment model and included (1) Establishing a Community Assessment Team (2) Collecting Community Data (3) Analyzing the County Health Data Book (4) Combining the County's Health Statistics with Community Data (5) Reporting to the Community (6) Selecting Health Priorities (7) Creating the Community Assessment Document (8) Developing a Community Health Action Plan [17]. Consequently, we performed a community-based SPP as

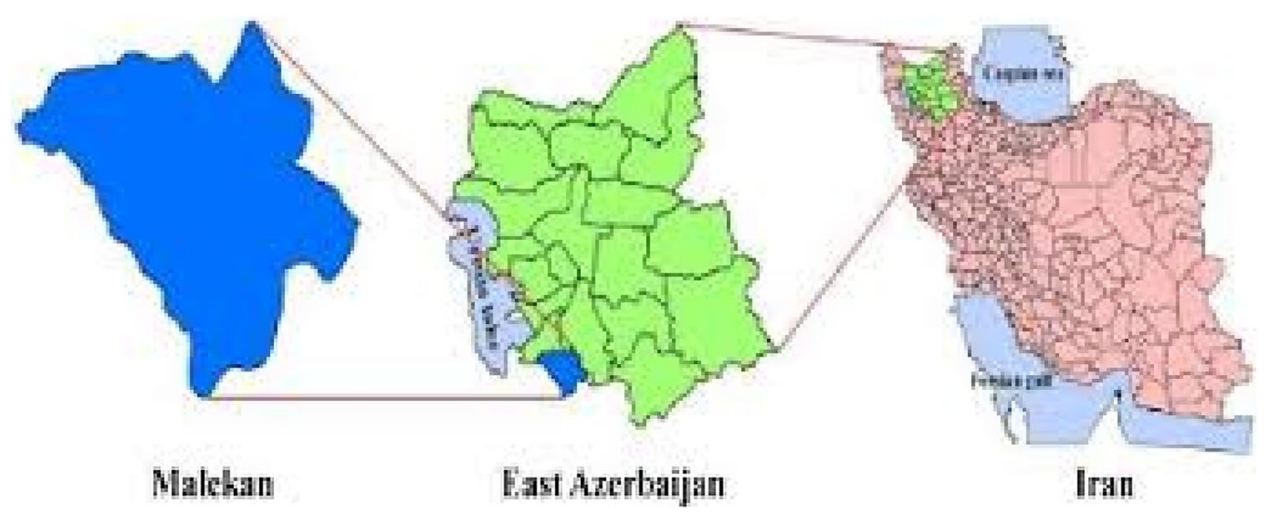

Fig. 1 Location of Malekan County in Iran 
stated in the eighth step (implementing an action plan for suicide prevention). This project was conducted in collaboration with the Department of Mental Health in Malekan County Health Network and the Research Center of Psychiatry and Behavior Sciences at Tabriz University of Medical Sciences. The target and study population were the general population of Malekan County, especially hotspot areas. In Iran, medical universities are responsible for the health system in each province. Iranian health system is based on Health Care Networks and thus the PHC provides the first line of health care services to assure access of all urban and rural populations by family physicians and various types of Health Service Providers (HSP). When patients need special health services, they are referred to the second level (county hospitals) by family physicians, and when higher specialty services are required, patients are referred to province referral hospitals with high specialty services $[18,19]$.

\section{Procedure}

Six steps were carried out for developing and implementing interventions including.

\section{Establishing an action research team}

This study was a process. For this process to be meaningful, team members and the health service providers from throughout the health system must be mobilized and all be involved during the research. We included academic members (Psychiatrists and Psychologists) from the Department of Psychiatry (School of Medicine) and executives from the Department of Mental Health (the provincial Deputy of Health), Tabriz University of Medical Sciences, and officers and health service providers from the County Health Network. The health service providers played as the engineer force in this project. Moreover, this team was used to select and prioritize effective programs and interventions for developing and implementing SPP.

\section{Developing and improving a registry for suicidal behaviors} The national registry for suicide was launched in 2009 in Iran and was based on reports from medical universities. In the counties, there isn't an electronic suicide registry system. The suicides are reported to province medical universities based on paper formats. Malekan County isn't so large and as it is known, suicides are underreported especially in small communities because of cultural barriers, stigma, and lack of an effective surveillance system.

Accordingly, we performed several efforts to increase the coverage of suicide registry in the county including (1) developing and using a simple and rapid checklist for collecting primary data in the emergency room of the hospitals, (2) Collecting information of SBs who were referred to the adjacent counties including Miyandowab, Bonab, and Maragheh, (3) Using native Community Health Workers (CHWs) (Behvarz in Persian) to obtain valid information from SBs and improving coverage of suicide and SA reporting and registration, (4) Improving intra-sectoral collaborations between Deputy of Health and Deputy of Treatment, (5) Improving inter-sectoral collaboration with clergy, village administrators and council members, municipalities, and governors with several advocacy activities.

\section{Identifying local determinants of SBs}

Suicide and SBs are affected strongly by social and cultural aspects. To identify and a better understanding of local effective factors of SBs, we carried out semistructured and face-to-face interviews with most SBs by trained clinical psychologists. The interviews were performed with the most nearby individuals of family members including parents, spouse or siblings instead of the suicide (died) cases. A valid and comprehensive questionnaire was used to collect effective factors on suicide and SBs such as demographic characteristics, socio-economic status, history of SA, psychological and depressive disorders, applied methods for suicide, season, and details of SBs, cultural and religious beliefs, and psychiatry and other determinants of suicide in a single and private setting.

The validity of this questionnaire was determined based on expert opinions including two psychiatrists, one epidemiologist, one community mental health expert, and one psychologist. Then some questions were revised. Its reliability was assessed with Cronbach's alpha test $(\alpha=0.78)$ among 20 participants.

\section{Training healthcare providers (gatekeepers)}

CHWs in PHC system of Iran have face-to-face contact with large numbers of community members as part of their usual routine performance. Each $\mathrm{CHW}$ provides mainly preventive healthcare services to approximately 1000 people. CHWs are supported and supervised by Community Health Extension Workers (CHEW) who are trained health care workers, psychologists, or public health staff, based on the linked health facilities. Many workshops and training sessions were conducted for CHWs, CHEWs, family Physicians, psychologists, and public health staff about details of the program and their practice. A comprehensive instruction included program details that were made available to all healthcare providers. 
Follow-up and monitoring of SBs to prevent re-attempts (risk assessment for suicide and depression)

History of SB and depressive disorders are robust predictors for suicide and future attempts. Case management of SAs was one of the most effective interventions to prevent re-attempts in the future. Figure 2 shows the algorithm of the follow up and monitoring of the SBs to prevent re-attempts.

After each SB has occurred, a paper-based file was created in the nearest health center. It was included the socio-demographic status of SBs and risk factors, medical histories, as well as depression and suicide risk assessment via Item 9 of the Patient Health Questionnaire (PHQ9). PHQ evaluates passive thoughts of death or self-injury within the last two weeks, and is often used to screen depressed patients for suicide risk [20].

All SB cases were followed by CHWs. According to the expert panel of this study, the risk of suicide and depression was assessed by PHQ. This tool was scored on a 3-point scale. The minimal (low-risk) score in PHQ ranges from 0 to 4 , moderate risk scores range from 5 to 14 , and severe risk is considered $\geq 15$ [21].

Moderate and low-risk cases were followed up (reassessed) by CHWs after 3 and 6 months, respectively. Severe cases were referred to the family physicians. Severe cases, after receiving care of family physicians, were referred to the psychiatrist in the County hospital (Farabi Hospital) if they had needed more specialized services or identified any psychiatric disorder. To prevent re-attempt cases, psychiatrists were used structured interviews to diagnose and treatment of depressive and other psychological disorders.

\section{Public awareness campaigns in hotspots}

In hot-spot areas, we held life-skills conferences and educating sessions with inter-sectoral collaborations (stakeholders and supporters of villages and cities) for heads of households, women, teenagers and youth and other at-risk populations. The life-skills education sessions were held by clinical psychologists and included parenting, effective communication, problem-solving, decision making, creative and critical thinking, and coping with stressful life events. These workshops were held in public sites such as the health center and mosques to be accessible to the general public.

Comprehensive and community-based campaigns have been implemented for improving knowledge, awareness, and attitude as well as depressive disorders and mental health-related issues of large numbers of the community. Coverage of free access to the mental health services included providing free drugs for major psychiatric disorders, school-based training and health-related services, marital counseling and other services were increased. Educational packages, posters, pamphlets, and banners were produced and distributed throughout the city and villages. The social stigma due to mental disorders and receiving psychological and mental health services from

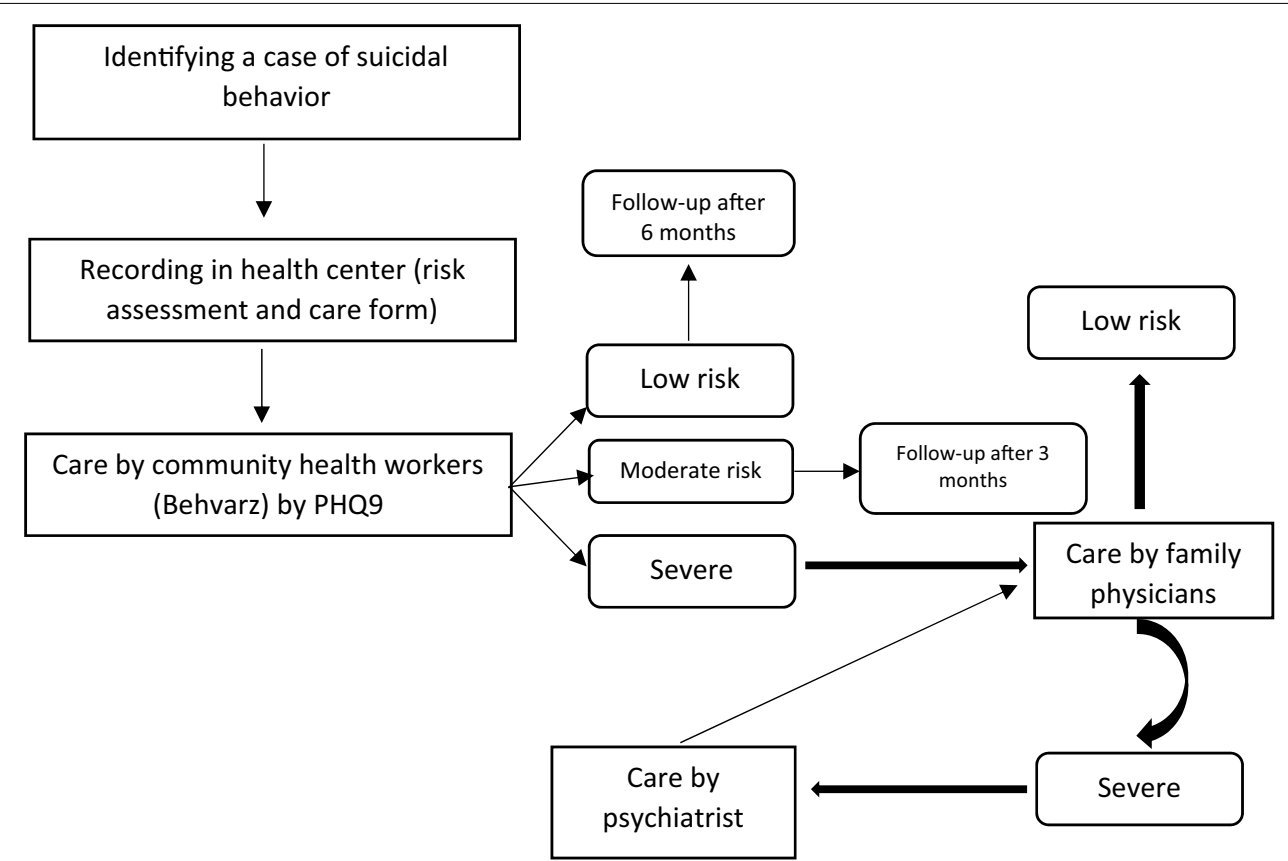

Fig. 2 Follow-up monitoring of suicidal behaviors to prevent re-attempts 
the public sector was reduced with performing the various training and mobilization practices.

\section{Outcomes}

Primary outcome was considered reduction of completed suicide. Secondary outcome was reduction of rates of SA and re-attempt. Our ultimate goal was to lower the rates of suicide, SA, and re-attempt till the study end by $15 \%$, $20 \%$ and $30 \%$, respectively.

\section{Statistical analysis}

The SPSS software (version 19.0, Chicago, IL, USA) was used for data analysis. Descriptive statistics and graphs were used to describe frequencies and ratios. Data normality was checked using the Kolmogorov-Smirnov test. Chi-square $(\mathrm{x} 2)$ test was used to compare binary or more categorical variables. T-test was used for comparison of continuous variables. Simple and multiple logistic regressions were used to estimate the crude and adjusted odds ratios (ORs) and 95\% confidence intervals (CIs) for suicide risk. In all tests, the confidence interval was considered $95 \%$ and $\mathrm{P}$-value $<0.05$ was significant.

\section{Results}

Table 1 summarizes suggested interventions for suicide and SB prevention in the general population in the Malekan County. Interventions for suicide prevention included follow-up monitoring of attempters, suicide risk assessment and treatment of depressive disorders, improving SBs registration, identifying risk factors of SBs, and implementation of public education campaigns in hotspots (Table 2).

Table 2 indicates the socio-demographic status of suicide cases and attempters in Malekan County during 2014-2017. A total of 821 SA and 32 suicide cases were found during the study course. The gender distribution for suicides was $70 \%$ male while the majority (64\%) of attempters were females. A significant association was found between completed suicide and male gender,

Table 1 Implemented interventions for suicide and suicide attempt preventions in Malekan County during 2014-17

\begin{tabular}{ll}
\hline Order & Interventions \\
\hline 1 & Establishing an action research team \\
2 & Improving registry for suicidal behaviors \\
3 & $\begin{array}{c}\text { Follow-up monitoring of suicide attempters to prevent re- } \\
\text { attempt (depression and suicide risk assessment) }\end{array}$ \\
4 & $\begin{array}{l}\text { Training healthcare providers (Gatekeeper) } \\
5\end{array}$ \\
$\begin{array}{l}\text { Identifying local determinants of suicidal behaviors and risk } \\
\text { factors }\end{array}$ & Public awareness campaigns in hotspots \\
\hline
\end{tabular}

age, occupation, family income, smoking, alcohol, and substance abuse $(P \leq 0.05)$. Regarding occupation, suicide deaths were lower among housewives $(\mathrm{P}=0.021)$. Moreover, higher education decreased the chance of completed suicide while its association with suicide was insignificant (OR: 0.70, 95\% CI 0.17-2.82).

Table 3 shows the descriptive epidemiology of participants in the County from 2014 to 2017. The hanging method $(62 \%)$ was the most frequent among suicide cases while the poisoning (75\%) was the most prevalent among SAs. The hanging method markedly increased suicide risk, 8.5 times (OR: 8.5, 95\% CI 2.9-76.99). Moreover, majority $(56.25 \%)$ of suicides occurred in spring.

More than one-third (1/3) of suicides had at least one time the history of SA. So, it was significantly associated with suicide risk (OR: 2.59, 95\% CI 1.086-6.17). Likewise, majority of suicides have occurred in the residential building (81.25\%).

Table 4 shows the results of multiple logistic regression analysis and estimating Adjusted Odds Ratios (AORs) and $95 \%$ Confidence Intervals (CIs) for suicide risk. After adjusting for the potential confounders, it was found age (26-40), male gender, higher income (more than 10 million Rials), and unemployment to be associated with the risk of suicide. Likewise, history of SA (AOR $=2.23$, 95\% CI 1.70-6.45), hanging method ( $\mathrm{AOR}=12.62,95 \% \mathrm{CI}$ 3.14-28.02), and season (spring) $(\mathrm{AOR}=3.56,95 \% \mathrm{CI}$ 2.19-9.63) were increased suicide risk.

Among all 821 SA which were assessed by PHQ 9 inventory tool, more than 288 (35\%) of SAs had a high risk (severe) for suicide (Table 5). During the implementation phase, a total of 93 life-skill and parenting education sessions were presented for targeted groups of adolescences, parents, and household heads in the hotspot areas of the County (Table 6).

Table 7 indicates the effect of the interventions on primary (suicide) and secondary outcomes (attempt and re-attempt) in Malekan County during 2014-17. Interventions demonstrated that both suicide and SA rates had declining trends in the County so that at the end of the study, 75 and $22 \%$ of completed suicide and SA decreased compared to before the study (2013). The incidence rate of suicide decreased in County from $11.22 / 100,000$ in 2013 (before the study) to 2.63 in 2017. Likewise, SA rate decreased from 203/100,000 in 2013 to 157 in 2017. Moreover, out of 821 suicide attempters, 67 (8.16\%) were collected from adjacent Counties included Miyandowab, Bonab and Marageh.

Figure 3 shows the implications of SPP on re-attempt trends and proportions. A decreasing trend was found during the study period from 2014 to 2017 . Re-attempt to attempt ratio was reduced from almost $12 \%$ in 2013 
Table 2 Socio-demographic characteristics and risk of suicide between suicides and suicide attempters in the Malekan County, from 2014-2017

\begin{tabular}{|c|c|c|c|c|}
\hline Variables & Attempters $(\mathrm{N}=821)$ & Suicides $(\mathrm{N}=32)$ & OR $(95 \% \mathrm{Cl})$ & P-value \\
\hline \multicolumn{5}{|l|}{ Gender } \\
\hline Female & $525(63.95)$ & $9(28.12)$ & 1 & 1 \\
\hline Male & $296(36.05)$ & $23(71.9)$ & $4.6(1.99-10.63)$ & 0.001 \\
\hline \multicolumn{5}{|l|}{ Age } \\
\hline $10-25$ & $504(61.39)$ & $9(28.125)$ & 1 & 1 \\
\hline $26-40$ & $241(29.35)$ & $18(56.25)$ & $4.22(1.75-10.15)$ & 0.001 \\
\hline$\geq 40$ & $76(9.25)$ & $5(15.63)$ & $3.76(1.1-12.92)$ & 0.035 \\
\hline \multicolumn{5}{|l|}{ Occupation } \\
\hline Student & $181(22.05)$ & $7(21.87)$ & 1 & 1 \\
\hline Farming related & $24(2.92)$ & $2(6.25)$ & $2.42(0.36-16.03)$ & 0.357 \\
\hline Housewife & $540(66.77)$ & $5(15.63)$ & $0.23(0.07-0.80)$ & 0.021 \\
\hline Unemployed or free & $76(9.25)$ & $18(56.25)$ & $1.43(0.68-3.17)$ & 0.038 \\
\hline \multicolumn{5}{|l|}{ Marital status } \\
\hline Single & $140(17.05)$ & $10(31.25)$ & 1 & 1 \\
\hline Married & $611(74.42)$ & $21(65.63)$ & $0.47(0.20-1.12)$ & 0.091 \\
\hline Widow and Divorced & $70(8.53)$ & $1(3.12)$ & $0.2(0.23-1.73)$ & 0.144 \\
\hline \multicolumn{5}{|l|}{ Educational level } \\
\hline Primary school & $277(33.74)$ & $10(31.25)$ & 1 & 1 \\
\hline Secondary school & $427(52.00)$ & $19(59.38)$ & $1.23(0.53-4.21)$ & 0.623 \\
\hline High school and Academic & $118(14.37)$ & $3(9.37)$ & $0.70(0.17-2.82)$ & 0.626 \\
\hline \multicolumn{5}{|l|}{ Family size } \\
\hline $2 \geq$ & $155(18.83)$ & $4(12.5)$ & $1.37(0.72-3.27)$ & 0.317 \\
\hline $3-4$ & $443(53.9)$ & $16(50.00)$ & & \\
\hline$\geq 4$ & $223(27.16)$ & $12(37.5)$ & & \\
\hline \multicolumn{5}{|l|}{ Income (Rials) } \\
\hline$<5$ million & $383(46.65)$ & $8(25.00)$ & 1 & 1 \\
\hline 5-10 million & $304(37.02)$ & $13(40.62)$ & $2.05(0.79-5.3)$ & 0.138 \\
\hline 10-20 million & $91(11.08)$ & $4(12.5)$ & $2.11(0.56-7.88)$ & 0.263 \\
\hline >20 million & $43(5.24)$ & $7(21.88)$ & $7.87(2.24-27.57)$ & 0.001 \\
\hline \multicolumn{5}{|l|}{ Resident } \\
\hline Urban & $166(20.22)$ & $2(6.25)$ & 1 & 1 \\
\hline Rural & $655(79.78)$ & $30(93.75)$ & $3.22(0.812-12.78)$ & 0.079 \\
\hline Live alone & $43(5.23)$ & $1(3.12)$ & $0.94(0.91-1.19)$ & 0.530 \\
\hline Substance abuse & $45(5.48)$ & $2(6.250$ & $1.11(1.00-1.27)$ & 0.042 \\
\hline Alcohol Consumption (daily) & $41(4.99)$ & $11(34.37)$ & $1.43(1.12-1.85)$ & 0.001 \\
\hline Smoking (daily) & $147(17.90)$ & $3(9.37)$ & $1.49(1.12-2.06)$ & 0.001 \\
\hline
\end{tabular}

(before the study) to 6.7\% in 2017. Compared to before the study, the re-attempt measure decreased $42 \%$.

\section{Discussion}

The present community-based SPP was implemented in Malekan County during 2014-2017. Primary outcome aimed to lower by $15 \%$ of completed suicide, and secondary outcomes also 20 and 30\% in SA and re-attempts, respectively. We found that interventions markedly decreased the rates of suicide and SA in the general population of Malekan County in all years of the study period. Suicide and SA were decreased from 12 to 203 per 100,000 in 2013 to 2.63 and 157 in 2017, respectively. In other words, at the end of this intervention study, almost 75 and $22 \%$ of suicide and suicide attempts were decreased, respectively.

Moreover, at the study end, a $42 \%$ decrease in reattempt proportion indicates the effectiveness of the study interventions. In the first year of the study (2014), developing a community-based registry for $\mathrm{SB}$ and 
Table 3 Descriptive epidemiology (methods, time and place) of suicide and suicide attempts in Malekan County during 2014-2017

\begin{tabular}{|c|c|c|c|c|}
\hline Variable & $\begin{array}{l}\text { Suicide } \\
N=32\end{array}$ & $\begin{array}{l}\text { Attempters } \\
\mathrm{N}=\mathbf{8 2 1}\end{array}$ & Crude OR $(95 \% \mathrm{CI})$ & P-value \\
\hline \multicolumn{5}{|l|}{ Methods } \\
\hline Hanging & $20(62.5)$ & $11(1.34)$ & $8.5(2.9-76.99)$ & 0.001 \\
\hline Poisoning & $8(25)$ & $613(74.66)$ & $0.63(0.18-2.24)$ & 0.483 \\
\hline Self-injury & $2(6.25)$ & 159 (19.37) & $0.446(0.12-1.78)$ & 0.236 \\
\hline Self-burning & $2(6.25)$ & $38(4.63)$ & 1 & 1 \\
\hline \multicolumn{5}{|l|}{ History of attempt } \\
\hline Yes & $8(25.0)$ & $47(5.72)$ & $2.59(1.086-6.17)$ & 0.028 \\
\hline No & $24(75.0)$ & $774(94.28)$ & 1 & 1 \\
\hline \multicolumn{5}{|l|}{ Place } \\
\hline Residential building & $26(81.25)$ & 747 (90.98) & $2.23(1.18-4.21)$ & 0.013 \\
\hline Un-residential building & $1(3.125)$ & $21(2.55)$ & & \\
\hline Outside & $5(15.62)$ & $53(6.45)$ & & \\
\hline \multicolumn{5}{|l|}{ Seasonal } \\
\hline Spring & $18(56.25)$ & $150(18.27)$ & 1 & 1 \\
\hline Summer & $3(9.37)$ & $288(35.8)$ & $0.089(0.024-0.32)$ & 0.001 \\
\hline Autumn & $2(6.25)$ & $259(31.54)$ & $0.066(0.014-0.30)$ & 0.001 \\
\hline Winter & $9(28.12)$ & $24(2.92)$ & $2.21(0.70-6.96)$ & 0.174 \\
\hline
\end{tabular}

Table 4 Measure of association and 95\% confidence intervals for suicide risk and effective factors by multiple logistic regression

\begin{tabular}{lll}
\hline Variables & Adjusted OR (95\% Cl) & P-value \\
\hline Age & 1 & 1 \\
$10-25$ & $6.34(2.1-19.15)$ & 0.001 \\
$26-40$ & $4.92(0.8-30.58)$ & 0.088 \\
$\geq 40$ & & \\
Gender & 1 & 1 \\
Female & $3.48(1.32-9.24)$ & 0.012 \\
Male & & \\
Income (Rials) & 1 & 1 \\
$\leq 10$ million & $2.68(1.06-5.41)$ & 0.049 \\
$>10$ million & & 1 \\
Occupation & 1 & 0.535 \\
Student & $2.49(0.138-45.05)$ & 0.032 \\
Farming or farming related & $0.198(0.045-0.86)$ & 0.006 \\
Housewife & $6.88(1.73-27.53)$ & \\
Self-employed or unemployment & & 0.001 \\
Attempt method & $12.62(3.14-28.02)$ & 0.001 \\
Hanging & & 1 \\
History of SA & $2.23(1.70-6.45)$ & \\
Yes & 1 & \\
No & $3.56(2.19-9.63)$ & \\
Season & & \\
Spring & &
\end{tabular}

Table 5 Suicide risk assessment among attempters by PHQ9

\begin{tabular}{llccc}
\hline Year & Attempters & \multicolumn{3}{l}{ PHQ scores } \\
\cline { 3 - 5 } & & Low (0-4) & Moderate (5-14) & Severe (15 $\leq$ ) \\
\hline 2014 & 251 & $51(20.32)$ & $114(45.42)$ & $86(34.26)$ \\
2015 & 202 & $42(2079)$ & $83(41.09)$ & $77(38.11)$ \\
2016 & 189 & $45(23.8)$ & $80(42.32)$ & $64(33.86)$ \\
2017 & 179 & $43(24.02)$ & $75(41.90)$ & $61(34.08)$ \\
Total & 821 & $181(22.05)$ & $352(42.87)$ & $288(35.08)$ \\
\hline
\end{tabular}

collecting SBs from adjunct counties increased the number of SAs. Despite this, the trend of suicide, SA, and re-attempts decreased during the study period with a smooth slope.

Keeping up with the literature and the WHO report for suicide prevention at the communities, developing and improving community-based registry for $\mathrm{SB}$, case management of persons who attempted suicide, identification and treatment of depression, training and public awareness campaigns and conducting research were found the most important and effective interventions to achieve the present study outcomes [22-26].

In our opinion, this community-based prevention and surveillance program is an effective and most applied health system research. We have tried to resolve this problem with the assistance and support of the health 
Table 6 Life-skills education sessions in the hot-spots during the suicide prevention program

\begin{tabular}{llll}
\hline Region/Area & Type of educating sessions & Number of sessions* & Target group \\
\hline Rural & Life-skill* $^{*}$ & 8 & Adolescents, young people and Households heads \\
& Parenting & 38 & Parents with children 12-2 years old \\
& Total & 46 & \\
Urban & Life-skill* & 15 & Adolescents, young people and Households heads \\
& Parenting & 32 & Parents with children 12-2 years old \\
Total & Total & 47 & \\
& 93 &
\end{tabular}

Each session performed at least 20 participants and lasted for $45 \mathrm{~min}$

* With component of effective communication, problem-solving, decision making, creative and critical thinking, and coping with stressful life events

Table 7 Primary and secondary outcomes ${ }^{*}$ of suicide prevention program in Malekan County, during 2014-2017

\begin{tabular}{|c|c|c|c|c|c|c|}
\hline \multirow[t]{2}{*}{ Year } & \multirow[t]{2}{*}{ Population } & \multicolumn{2}{|c|}{ Suicide $(\mathrm{N}=32)$} & \multicolumn{2}{|l|}{ Suicide attempters } & \multirow{2}{*}{$\begin{array}{l}\text { Attempt } \\
\text { to suicide } \\
\text { ratio }\end{array}$} \\
\hline & & $\mathrm{N}$ & Rate(per 100,000$)$ & $\begin{array}{l}\text { Attempters } \\
\mathrm{N}=\mathbf{8 2 1}\end{array}$ & $\begin{array}{l}\text { Collected through } \\
\text { adjacent counties** }\end{array}$ & \\
\hline $\begin{array}{l}2013 \text { (before } \\
\text { study) }\end{array}$ & 107,000 & 12 & 11.22 & $\begin{array}{l}217 \\
(203 \text { per } 100,000)\end{array}$ & No data available & 18.083 \\
\hline 2014 & 109,000 & 9 & 8.25 & $\begin{array}{l}251 \\
(230 \text { per } 100,000)\end{array}$ & $17(6.77)$ & 27.88 \\
\hline 2015 & 111,000 & 5 & 4.50 & $\begin{array}{l}202 \\
(182 \text { per } 100,000)\end{array}$ & $21(10.4)$ & 40.40 \\
\hline 2016 & 112,000 & 5 & 4.46 & $\begin{array}{l}189 \\
(169 \text { per } 100,000)\end{array}$ & $16(8.4)$ & 37.50 \\
\hline 2017 & 114,000 & 3 & 2.63 & $\begin{array}{l}179 \\
(157 \text { per } 100,000)\end{array}$ & $13(7.25)$ & 59.66 \\
\hline Total & & 32 & $\begin{array}{l}\text { Reduction at the end }=75 \% \\
(11.22-2.63 / 11.22)\end{array}$ & $\begin{array}{l}\text { Reduction at the end }=22 \% \\
(203-157 / 203)\end{array}$ & $67(8.16)$ & - \\
\hline
\end{tabular}

*The primary outcome: suicide; Secondary outcome: suicide attempt and re-attempt

**Miyandowab, Bonab and Maragheh

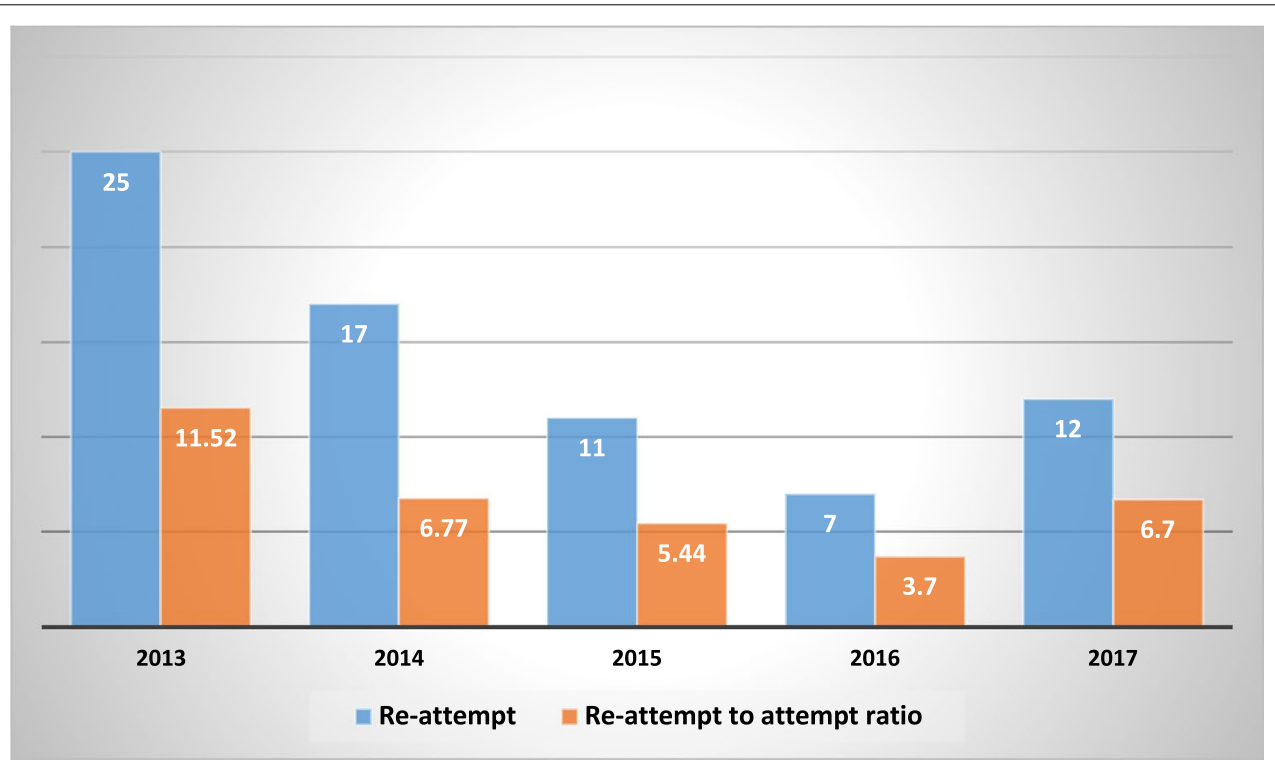

Fig. 3 Trend of re-attempt distribution and ratio of re-attempt to attempt during study period (2014-2017) in Malekan County, Iran 
system after identifying the problem, similar to action research. We organized the health system in line with our purpose for achieving the study outcome measures and improving a problem-solving perspective between healthcare providers. It was needed more practice and coordination.

We tried to obtain the support of health managers, county decision-makers and stakeholders with many advocacies efforts. We have used the influence of the clergy, and stockholders among County people for implementing the study interventions and educational programs. The evidence has shown effective efforts to reduce suicide would need pooled interventions by different providers in several fields [27].

Furthermore, in Iran, health system and health services are provided based on PHC and Health Care Networks. $\mathrm{PHC}$ is an effective and appropriate place for developing and management of SPPs with various types of healthcare providers in particular community health workers. Community healthcare workers have face-to-face contact with large numbers of community members as part of their routine performance. Around the world, many suicide prevention programs in various designs (RCT, descriptive, qualitative and other methods) had been performed [28]. However, this study carried out in limited resource with community-based interventions, as could provide a comprehensive framework for low and middle-income settings.

In most studies, SPP and strategies focus on increasing access to psychological health services for at-risk people via general practitioners and restricting access to means of self-harm/suicide [29-31]. In addition to the above-mentioned interventions, this study emphasized remarkable interventions that included case registration, case management of attempters, public awareness campaigns, treatment of depression, training of health service providers, conducting research, and social and economic factors related to suicide prevention.

The annual decrease of re-attempters shows the appropriateness and effectiveness of the present study interventions. Management of persons who attempted suicide is one of the most effective recommendations also reported by the WHO. The risk of re-attempt after SA was high in the months following an attempt. This finding is also in agreement with previous studies [32,33].

Globally suicide is a priority condition. A national SPP is necessary through a stepwise approach at the local level. A SPP at the national level not only explains the aim and magnitude of the problem but more remarkably, identifies that SB is a critical public health problem. SPP should recommend a comprehensive evaluation and monitoring framework to measure the effectiveness of interventions. Prevention of suicide is a collective responsibility and should be organized by the political commitment of governments and civil society throughout the world [34].

Moreover, findings of the present study showed that demographic characteristics (male gender, age 26-40, living in rural area), and socio-economic status (loweducation, low-occupational status (unemployment), high-income), and behavioral-factors (tobacco and alcohol abuse) were associated with completed suicide. In agreement with our findings, a systematic review study revealed that low socio-economic status, low-education, and low occupational status were related to suicide risk [35]. Likewise, a study from England and other countries found that socio-demographic characteristics and low socio-economic status were directly associated with suicide and SBs [36, 37]. In the present study, suicide was common among high-income families while SAs were prevalent among low-income families. Another review study found low economic status, and unemployment to be associated with SBs [38].

\section{Strengths and limitations}

The main strength of this study was the use of multidimensional practical interventions that resulted in significant achievement on suicide prevention. Another strength was using and integrating action and research to achieve study measures.

The present study had a limitation. This study was conducted in a small area with limited population. So, application of its methods and findings in large communities should be with caution.

\section{Conclusions}

Findings at the study end indicated that interventions achieved predetermined aims and outcomes. Primary outcome (suicide) lowered by $75 \%$, and secondary outcomes (attempt and re-attempt) reduced 22 and $42 \%$, respectively.

In this study, developing and improving a registry for suicide and suicidal behaviors, case management of suicide attempters, training healthcare providers, public awareness campaigns in hot spots, and conducting localresearch were found as effective interventions and strategies for suicide prevention. The findings of this study can provide valuable evidence and framework for the Malekan County and national mental health programs.

Moreover, findings showed that socio-economic status and socio-demographic characteristics were associated with lethal suicide. These economic, structural, and socio-cultural issues serve as barriers to the implementation of SPPs. These findings challenge the personal riskfactor models of SPP and highlight the need to consider a 
wide range of contextual and socio-economic, and sociocultural factors when implementing SPPs [39].

The practical framework that appeared in this study could be used to develop SPPs and suicide researches in Iranian context. This study also provides an excellent prospect to bridge the gap between research and field programs and/or policy. These all recommend the need to reinforce the awareness about SBs and evaluate the efficiency of the national health approach in addressing the issues of suicide and SBs [40].

\section{Specific suggestions}

Improving suicide registry coverage: this finding suggests that the first pillar for developing an effective SPP and/or strategy is to establish an electronic registry for suicide which is also emphasized by the WHO.

Advocacy and inter-sectoral collaborations: Strong political commitment and significant social actions are needed at the grass-root level for implementing an SPP. Therefore, the SPP should be customized with a comprehensive policy and with a multidimensional approach that includes active cooperation between the various sectors of government, health sectors, social welfare, stakeholders, clerics, urban and rural development experts, legal affairs, and especially general population and their participation [41].

Combined actions with local researches (actionresearch): Predictors and patterns of suicide and suicidal behaviors are affected strongly by local level religion and customs. Therefore, to achieve significant implications, should integrate research and action, and the interventions should be developed based on local-evidence. Despite the amplified focus of health managers and policymakers on the significance of suicide prevention strategies, findings confirm an evidence gap in research knowledge regarding program development, planning, and effective outcomes, and there remains a need for the integration of research and knowledge utilization [42, 43].

Case management of SBs: Findings of the present study revealed that integrated case management and followup monitoring of SBs are low-cost and feasible strategies that can reduce suicide and SBs. However, sub-interventions should be selected via high-evidence and expert testimony.

\section{Abbreviations}

SPP: Suicide prevention program; SBs: Suicidal behaviors; SA: Suicide attempt; PHC: Primary health care; CHWs: Community health workers; PHQ: Patient health questionnaire.

\section{Acknowledgements}

We express our gratitude to our colleagues in the Malekan Health Center, department of mental health and we also thank the support of "Clinical
Research Development Unit, Razi Psychiatric Hospital", Tabriz University of Medical Sciences, Tabriz, Iran.

\section{Authors' contributions}

HA: developed original idea and protocol, did interpretation and analysis of the data, data collection and drafted and edited all sections of the manuscript. AF and MF contributed in the design, preparing the manuscript draft. MM: contributed to the protocol development and interpretation. EDE: contributed to the manuscript development and interpretation of the data, and data collection and drafted all sections of the manuscript. All authors read and approved the final manuscript.

\section{Funding}

This study was financially supported by Tabriz University of Medical Sciences to number 60665, and it was done with supervising of Research Center of Psychiatry and Behaviors Sciences. All research sections were fund by Tabriz University of Medical Sciences. Sponsor of the study had no role in data collection and/or analysis nor interpretation.

\section{Availability of data and materials}

The datasets generated and/or analyzed during the current study are not publicly available due to the sensitivity of the suicide issue and the confidentiality of the information, the consent of the sponsoring organization is required. But are available from the corresponding author on reasonable request.

\section{Declarations}

\section{Ethics approval and consent to participate}

This study was approved by the ethics committee of Tabriz University of Medical Sciences with number: TBZMED.REC.1394.674. Written informed consent was obtained from all subjects before the interview. For subjects who were under 18 years, we have obtained written informed consent from the father or guardian of the participants in a face to face position with explanation of the purpose of the study.

\section{Consent for publication}

The funding organization and all authors have consent for publication.

\section{Competing interests}

The authors declare that they have no competing interests.

\section{Author details}

${ }^{1}$ Social Determinants of Health Research Center, Health Management and Safety Promotion Research Institute, Tabriz University of Medical Sciences, Tabriz, Iran. ${ }^{2}$ Research Center of Psychiatry and Behavioral Sciences, Tabriz University of Medical Sciences, Tabriz, Iran. ${ }^{3}$ Department of Epidemiology and Biostatistics, School of Public Health, Tehran University of Medical Sciences, Tehran, Iran. ${ }^{4}$ Medical Education Research Center, Tabriz University of Medical Sciences, Tabriz, Iran. ${ }^{5}$ Road Traffic Injury Research Center, Tabriz University of Medical Sciences, Tabriz, Iran. ${ }^{6}$ Malekan Health Center, Tabriz University of Medical Sciences, Tabriz, Iran.

Received: 19 May 2020 Accepted: 27 July 2021

Published online: 04 August 2021

\section{References}

1. Maina R, Bukusi D, Kumar M. Suicide prevention by emergency nurses: perceived self-efficacy in assessment, management and referral at Kenyatta National Hospital in Kenya. Ann Gener Psychiatry. 2019;1 8:16.

2. Li F, Yip PS. How to make adjustments of underreporting of suicide by place, gender, and age in China? Soc Psychiatry Psychiatr Epidemiol. 2020:55:1133-43.

3. Tøllefsen IM, Hem E, Ekeberg $\varnothing$. The reliability of suicide statistics: a systematic review. BMC Psychiatry. 2012;12:1-11.

4. The LGH. Suicide prevention: keeping the momentum. Lancet Glob Health. 2017;5:e838. 
5. Hagaman AK, Maharjan U, Kohrt BA. Suicide surveillance and health systems in Nepal: a qualitative and social network analysis. Int J Ment Health Syst. 2016;10:46.

6. Hauge L, Stene-Larsen K, Grimholt TK, Øien-Ødegaard C, Reneflot A. Use of primary health care services prior to suicide in the Norwegian population 2006-2015. BMC Health Serv Res. 2018;18:619.

7. Tsegay A, Damte A, Kiros A. Determinants of suicidal ideation among patients with mental disorders visiting psychiatry outpatient unit in Mekelle town, psychiatric clinics, Tigray, Northern Ethiopia: a case-control study. Ann Gen Psychiatry. 2020;19:1-12.

8. Bertolote JM, Fleischmann A, Butchart A, Besbelli N. Suicide, suicide attempts and pesticides: a major hidden public health problem. In: Book Suicide, suicide attempts and pesticides: a major hidden public health problem. City: SciELO Public Health; 2006.

9. Zhou W, Xiao S. Existing public health surveillance systems for mental health in China. Int J Ment Health Syst. 2015;9:3.

10. Nsubuga P, Nwanyanwu O, Nkengasong JN, Mukanga D, Trostle M. Strengthening public health surveillance and response using the health systems strengthening agenda in developing countries. BMC Public Health. 2010;10:5

11. Schulberg HC, Bruce ML, Lee PW, Williams JW Jr, Dietrich AJ. Preventing suicide in primary care patients: the primary care physician's role. Gen Hosp Psychiatry. 2004;26:337-45.

12. Saberi-Zafaghandi MB, Hajebi A, Eskandarieh S, Ahmadzad ASLM. Epidemiology of suicide and attempted suicide derived from the health system database in the Islamic Republic of Iran 2001-2007. Eastern Mediterranean Health J. 2012;18(8):836-41.

13. Farahbakhsh M, Fakhari A, Davtalab Esmaeili E, Azizi H, Mizapour M, Asl Rahimi V, Hashemi L. The role and comparison of stressful life events in suicide and suicide attempt: a descriptive-analytical study. Iran J Psychiatry Behav Sci. 2020;14:1.

14. Ahmadi A, Mohammadi R, Stavrinos D, Almasi A, Schwebel DC. Selfimmolation in Iran. J Burn Care Res. 2008;29:451-60.

15. Organization WH. Public health action for the prevention of suicide: a framework. Geneva: World Health Organization; 2012.

16. Fakhari A, Farahbakhsh M, Azizi H, Esmaeili ED, Mirzapour M, Rahimi VA, Hashemi L, Gaffarifam S. Early marriage and negative life events affect on depression in young adults and adolescents. Arch Iran Med. 2020;23:90-8.

17. Alfano-Sobsey E, Ledford SL, Decosimo K, Horney JA. Community health needs assessment in Wake County, North Carolina: partnership of public health, hospitals, academia, and other stakeholders. North Carolina Med J. 2014;75:376-83.

18. Malakouti SK, Nojomi M, Poshtmashadi M, et al. Integrating a suicide prevention program into the primary health care network: a field trial study in Iran. Biomed Res Int. 2015;2015:193729. https://doi.org/10.1155/ 2015/193729.

19. Azizi H, Davtalab-Esmaeili E, Farahbakhsh M, Zeinolabedini M, Mirzaei Y, Mirzapour M. Malaria situation in a clear area of Iran: an approach for the better understanding of the health service providers' readiness and challenges for malaria elimination in clear areas. Malar J. 2020;19:1-10.

20. Na PJ, Yaramala SR, Kim JA, Kim H, Goes FS, Zandi PP, Voort JLV, Sutor B, Croarkin P, Bobo WV. The PHQ-9 Item 9 based screening for suicide risk: a validation study of the Patient Health Questionnaire (PHQ) - 9 Item 9 with the Columbia Suicide Severity Rating Scale (C-SSRS). J Affect Disord. 2018;232:34-40.

21. Rossom RC, Coleman KJ, Ahmedani BK, Beck A, Johnson E, Oliver M, Simon GE. Suicidal ideation reported on the PHQ9 and risk of suicidal behavior across age groups. J Affect Disord. 2017;215:77-84.

22. Kalafat J. School approaches to youth suicide prevention. Am Behav Sci. 2003:46:1211-23.

23. Szanto K, Kalmar S, Hendin H, Rihmer Z, Mann JJ. A suicide prevention program in a region with a very high suicide rate. Arch Gen Psychiatry. 2007;64:914-20.

24. Chitty KM, Schumann JL, Schaffer A, Cairns R, Gonzaga NJ, Raubenheimer JE, Carter G, Page A, Pearson S-A, Buckley NA. Australian Suicide Prevention using Health-Linked Data (ASHLi): Protocol for a population-based case series study. BMJ Open. 2020;10:e038181.

25. Mann JJ, Apter A, Bertolote J, Beautrais A, Currier D, Haas A, Hegerl U, Lonnqvist J, Malone K, Marusic A. Suicide prevention strategies: a systematic review. Jama. 2005;294:2064-74.
26. Van der Feltz-Cornelis CM, Sarchiapone M, Postuvan V, Volker D, Roskar S, Grum AT, Carli V, McDaid D, O'Connor R, Maxwell M. Best practice elements of multilevel suicide prevention strategies. Crisis. 2011;32(6):31933. https://doi.org/10.1027/0227-5910/a000109.

27. Organization WH: National suicide prevention strategies: progress, examples and indicators. 2018.

28. Hofstra E, Elfeddali I, Metz M, Bakker M, de Jong JJ, van Nieuwenhuizen C, Van der Feltz-Cornelis CM. A regional systems intervention for suicide prevention in the Netherlands (SUPREMOCOL): study protocol with a stepped wedge trial design. BMC Psychiatry. 2019;19:1-17.

29. Cox GR, Owens C, Robinson J, Nicholas A, Lockley A, Williamson M, Cheung YTD, Pirkis J. Interventions to reduce suicides at suicide hotspots: a systematic review. BMC Public Health. 2013;13:214.

30. Kataoka S, Stein BD, Nadeem E, Wong M. Who gets care? Mental health service use following a school-based suicide prevention program. J Am Acad Child Adoles Psychiatry. 2007:46:1341-8.

31. Bonvoisin T, Utyasheva L, Knipe D, Gunnell D, Eddleston M. Suicide by pesticide poisoning in India: a review of pesticide regulations and their impact on suicide trends. BMC Public Health. 2020;20:1-16.

32. Parra-Uribe I, Blasco-Fontecilla H, Garcia-Parés G, Martínez-Naval L, Valero-Coppin O, Cebrià-Meca A, Oquendo MA, Palao-Vidal D. Risk of re-attempts and suicide death after a suicide attempt: a survival analysis. BMC Psychiatry. 2017;17:163.

33. Irigoyen M, Porras-Segovia A, Galván L, Puigdevall M, Giner L, De Leon S, Baca-García E. Predictors of re-attempt in a cohort of suicide attempters: a survival analysis. J Affect Disord. 2019;247:20-8.

34. Thompson LH, Lang JJ, Olibris B, Gauthier-Beaupré A, Cook H, Gillies D, Orpana H. Participatory model building for suicide prevention in Canada. Int J Ment Health Syst. 2020;14:1-9.

35. Li Z, Page A, Martin G, Taylor R. Attributable risk of psychiatric and socioeconomic factors for suicide from individual-level, population-based studies: a systematic review. Soc Sci Med. 2011;72:608-16.

36. Aschan L, Goodwin L, Cross S, Moran P, Hotopf M, Hatch S. Suicidal behaviours in South East London: prevalence, risk factors and the role of socio-economic status. J Affect Disord. 2013;150:441-9.

37. Ayehu M, Solomon T, Lemma K. Socio-demographic characteristics, clinical profile and prevalence of existing mental illness among suicide attempters attending emergency services at two hospitals in Hawassa city, South Ethiopia: a cross-sectional study. Int J Ment Health Syst. 2017;11:1-9.

38. lemmi V, Bantjes J, Coast E, Channer K, Leone T, McDaid D, Palfreyman A, Stephens B, Lund C. Suicide and poverty in low-income and middleincome countries: a systematic review. Lancet Psychiatry. 2016;3:774-83.

39. Goldstone D, Bantjes J. Mental health care providers' perceptions of the barriers to suicide prevention amongst people with substance use disorders in South Africa: a qualitative study. Int J Ment Health Syst. 2017;11:1-11.

40. Bifftu BB, Tiruneh BT, Dachew BA, Guracho YD. Prevalence of suicidal ideation and attempted suicide in the general population of Ethiopia: a systematic review and meta-analysis. Int J Ment Health Syst. 2021;15:27.

41. Zalsman G, Hawton $K$, Wasserman D, van Heeringen $K$, Arensman E, Sarchiapone M, Carli V, Höschl C, Barzilay R, Balazs J. Suicide prevention strategies revisited: 10-year systematic review. Lancet Psychiatry. 2016;3:646-59.

42. Schlichthorst M, Ozols I, Reifels L, Morgan A. Lived experience peer support programs for suicide prevention: a systematic scoping review. Int J Ment Health Syst. 2020;14:1-12.

43. Fakhari A, Farahbakhsh M, Esmaeili ED, et al. A longitudinal study of suicide and suicide attempt in northwest of Iran: incidence, predictors, and socioeconomic status and the role of sociocultural status. BMC Public Health. 2021;21:1486. https://doi.org/10.1186/s12889-021-11527-9.

\section{Publisher's Note}

Springer Nature remains neutral with regard to jurisdictional claims in published maps and institutional affiliations. 